\title{
Pulmonary lesions following intravenous inoculation with a high concentration of Staphylococcus aureus in pigs
}

Sørensen, Karen Elisabeth; Nielsen, Ole Lerberg; Jensen, Henrik Elvang; Leifsson, Páll S.; Iburg, Tine Moesgaard

Published in:

Journal of Comparative Pathology

Publication date:

2010

Document version

Publisher's PDF, also known as Version of record

Citation for published version (APA):

Sørensen, K. E., Nielsen, O. L., Jensen, H. E., Leifsson, P. S., \& Iburg, T. M. (2010). Pulmonary lesions following intravenous inoculation with a high concentration of Staphylococcus aureus in pigs. Journal of Comparative Pathology, 143(4), 324.

http://www.sciencedirect.com.ep.fjernadgang.kb.dk/science/article/pii/S0021997510001751 


\section{Journal of}

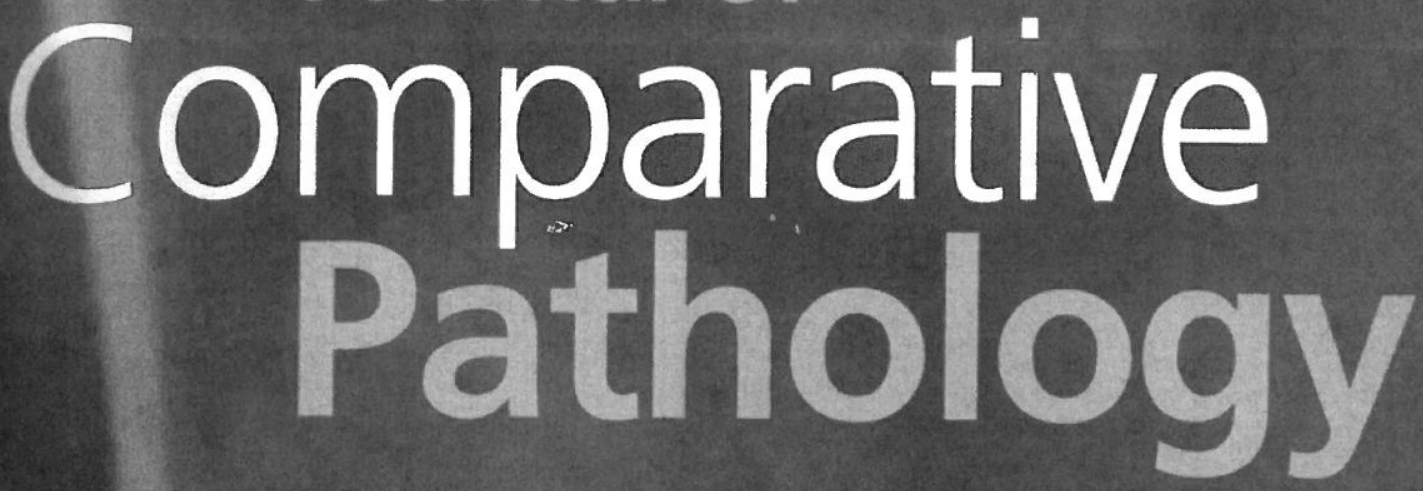

FOUNDED IN 1888 BY JOHN M'FADYEAN

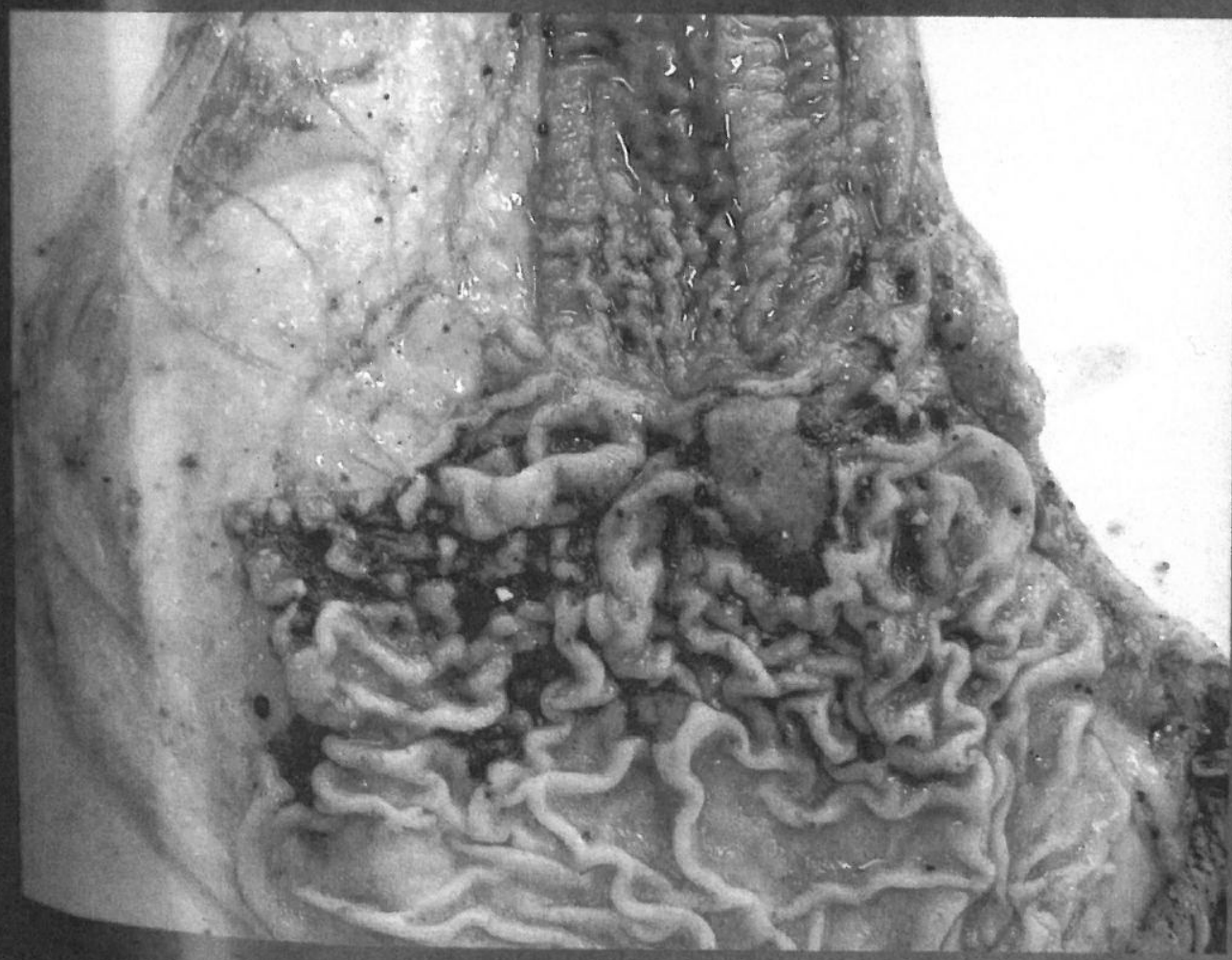




\section{P9}

\section{DISTRIBUTION PATTERNS OF AVIAN BORNAVIRUS IN PSITTACINE BIRDS SUFFERING FROM PROVENTRICULAR DILATATION DISEASE}

S. Reßmeyer, S. Herzog, D. Enderlein, U. Heffels-Redmann, M. Lierz, C. Herden and A. Buchinder Juslus-Liebig-University Gießen, Germany

Introduction: Avian bornavirus genotypes (ABV) have been identified in psittacines that died from proventricular dilatation disease (PDD).

Materials and Methods: Brain, spinal cord, retina, nervus ischiadicus, crop, gizzard, proventriculus, intestine, myocardium, liver, kidney, pancreas, skin and skeletal muscle were investigated in 65 birds (of seven different species) that were suspected of having $\mathrm{PDD}$. HE staining was used for histological evaluation and $\mathrm{ABV}$ antigen was demonstrated immunohistochemically by application of an anti-phoshoprotein antibody. Data were compared to the detection of viral RNA by real time RT-PCR (38/53 birds), ABV-specific antibodies (6/9 birds) and isolation of infectious virus (16/19 birds).

Results: Virus antigen was restricted to the central nervous system in four birds, but was found also in the periphery in 20 birds. In 22 of the birds virus antigen was detectable only in the periphery and in 19 cases no viral antigen was found. Viral antigen detection correlated with the presence of viral RNA in 28 cases, with detection of ABV-specific serum antibodies in six birds and with isolation of infectious virus in 16 birds.

Conclusions: Whether different viral distribution patterns were due to infection with different viral genotypes, represent different stages of infection or are mainly determined by host factors requires further investigation.

\section{P10}

PULMONARY LESIONS FOLLOWING INTRAVENOUS INOCULATION WITH A HIGH CONCENTRATION OF STAPHYLOCOCCUS AUREUS IN PIGS

K.E. Soerensen, O.L. Nielsen, H.E. Jensen, P.S. Leifsson and T.M. Iburg

Department of Veterinary Disease Biology, Denmark

Introduction: Following intravenous inoculation of Staphylococcus aureus, pigs are prone to develop low-grade sepsis. The porcine lung plays an important role in clearing systemic bacterial infections. We investigated pulmonary changes after increasing the concentration of $S$. aureus in the inoculum.

Materials and Methods: Five pigs were inoculated intravenously with $S$. aureus $\left(1 \times 10^{8} \mathrm{CFU} / \mathrm{kg}\right.$ body weight $)$ and two control animals were sham-inoculated. Blood samples for bacterial culture were taken at regular intervals before and after inoculation. At $48 \mathrm{~h}$ post-inoculation all animals were killed and subject to necropsy examination. Tissue was collected for histological examination.

Results: All five infected animals had disseminated pulmonary abscessation with thickening of surrounding alveolar septa. Areas of necrosis, haemorrhage, fibrinous exudation and oedema were seen in two pigs. After $6 \mathrm{~h}$ most infected animals had cleared the bacteria from the blood; however, high concentrations were found in the lungs post morlem. The pulmonary lesions were more severe compared with those of earlier studies using the same bacterial dose suspended in a higher volume.

Conclusions: More severe pulmonary changes are observed with an increased inoculum concentration of $S$. aureus. The observed lesions may be associated with focal cytokine release within the lungs.

\section{P11}

\section{ORIGIN OF THE WORLD FROG PANDEMIC: EVIDENCE FROM EAST ASIA SUPPORTS THE NOVEL PATHOGEN THEORY \\ U. Yumi ${ }^{*}$, G. Koichi ${ }^{\dagger}$ and O. Hidetoshi \\ * Azabu University, ${ }^{\dagger}$ National Institute for Environmental Studies and ${ }^{\ddagger}$ University of Hyogo, Japan}

Introduction: The pandemic caused by the chytrid fungus Batrachochylrium dendrobatidis (Bd) is considered to be partly responsible for the precipitous decline in amphibian populations worldwide; however, the effect has not yet been seen in Asia. The aim of the present study was to determine why no effects of Bd have been reported in Japan. Materials and Methods: A pathological and molecular biological examination was conducted on 28 native Japanese giant salamanders (Andrias japonicus; AJ) to clarify the prevalence of $\mathrm{Bd}$. Ten animals were collected between 2005-2008 and 18 were collected between 1902-1937.

Results: Bd infection was confirmed in 13 salamanders. Of these, the earliest infected specimens were seven cases collected in 1902. The base sequence of the ITS-1 region of the amplified PCR product (DDBJ No. AB435220) was slightly different from that of Bd registered with DDBJ. However, the genetic base sequence of the $18 \mathrm{~S}$ and $28 \mathrm{~S}$ rRNA specific gene amplified from AJ was the same as that of the registered $\mathrm{Bd}$

Conclusions: Until now, the earliest recorded occurrence of $\mathrm{Bd}$ anywhere in the world was that found in Xenopus laevis in South Africa in 1938. The finding of infection in a case dating from 1902 suggests an Asian origin for this fungal infection.

\section{P12}

\section{SYSTEMIC MYCOSIS DUE TO CANDIDA ALBICANS INFECTION IN A DOG \\ M. Skoric* , P. Fictum * and I. Pavlik ${ }^{\dagger}$ \\ ${ }^{*}$ University of Veterinary and Pharmaceutical Sciences and ${ }^{\dagger}$ Veterinary Research Institute, Czech Republic}

Introduction: Systemic mycotic infection was diagnosed in a 2-yearold female hovawart presented with generalized lymphadenopathy. Pyogranulomatous inflammation was found in the lymph nodes spleen, liver, kidneys, adrenal glands, peritoneum, lungs, myocardium and mammary gland.

Materials and Methods: Tissue samples were collected for histopathological examination, fixed in $10 \%$ neutral buffered formalin, dehydrated, embedded in paraffin wax, sectioned on a microtome $(4 \mu \mathrm{m})$ and stained with haematoxylin and eosin (HE), Ziehl-Neelsen (ZN) and periodic acid-Schiff (PAS) for the detection of infectious agents in tissues. Samples of all affected organs were taken for fungal culture.

Results: At necropsy examination, white nodules of various sizes were found in lymph nodes, spleen, liver, kidneys, adrenal glands, peritoneum, lungs, myocardium and mammary gland. Microscopically, these were pyogranulomas consisting of neutrophils, macrophages and multinucleated giant cells, often with necrotic centres. In all of the pyogranulomas there were PAS-positive fungal structures.

Conclusions: Diagnosis of generalized candidiasis was confirmed after Candida albicans was cultured from the lesions. 